Pesq. Vet. Bras. 29(4):291-294, abril 2009

\title{
Evaluation of left ventricular diastolic echocardiographic parameters in healthy dogs by pulsed-wave Doppler ${ }^{1}$
}

\author{
Guilherme G. Pereira ${ }^{2 *}$, Liliam C. Petrus², André L.F. Santos², Fernanda L. \\ Yamaki $^{2}$ and Maria Helena M.A. Larsson ${ }^{3}$
}

\begin{abstract}
Pereira G.G., Petrus L.C., Santos A.L.F., Yamaki F.L. \& Larsson M.H.M.A. 2009. Evaluation of left ventricular diastolic echocardiographic parameters in healthy dogs by pulsed-wave Doppler. Pesquisa Veterinária Brasileira 29(4):291-294. Departamento de Clínica Médica, Faculdade de Medicina Veterinária e Zootecnia, Universidade de São Paulo, Av. Prof. Orlando Marques de Paiva 87, São Paulo, SP 05508-900, Brazil. E-mail: ggpereira2002@yahoo.com.br

Left ventricular diastolic dysfunction plays an important role on heart failure progression. In order to obtain additional reference values of left ventricular diastolic parameters and investigate influence of common variables, peak E wave (peak E), peak A wave (peak A), E/A ratio (E/A), E wave deceleration time (EDT) and isovolumic relaxation time (IRVT) were studied in 40 clinically healthy dogs, by pulsed wave Doppler. The following values were obtained: peak $E=0.747 \pm 0.117 \mathrm{~m} / \mathrm{s}$, peak $A=0.487 \pm 0.062 \mathrm{~m} / \mathrm{s}, E / A=1.533 \pm$ $0.198, E D T=88.7 \pm 9.2 \mathrm{~ms}$ and IRVT $=0.080 \pm 0.009 \mathrm{~s}$. Some parameters were influenced by heart rate (peak E, peak $A$ and IRVT), by age (peak $A$ and $E / A$ ) and by body weight (TRIV). Gender influence was absent. Values obtained can be used as reference for canine specimens but its interpretation should consider on the influence of related variables.
\end{abstract}

INDEX TERMS: Diastole, pulsed-wave Doppler, Dogs, Left ventricle.

RESUMO.- [Avaliação de parâmetros ecocardiográficos diastólicos do ventrículo esquerdo de cães saudáveis por meio de Doppler pulsátil.] A disfunção diastólica do ventrículo esquerdo contribui de maneira importante para a progressão da insuficiência cardíaca. No intuito de obter valores de referência adicionais para os parâmetros diastólicos do ventrículo esquerdo e para investigar a influência de variáveis comuns, estudou-se, por meio de Doppler pulsátil, a velocidade máxima da onda $E$ (Vmáx.E), a velocidade máxima da onda $A$ (Vmáx.: $A)$, a relação $E / A(E / A)$, o tempo de desaceleração da onda $E$ (TDE) e o tempo de relaxamento isovolumétrico (TRIV) em 40 cães clinicamente saudáveis. Os seguintes valores foram obtidos: Vmáx.E $=0,747 \pm 0,117 \mathrm{~m} / \mathrm{s}, V \operatorname{máx} \cdot A=0,487 \pm 0,062 \mathrm{~m} / \mathrm{s}, E / A=$

\footnotetext{
${ }^{1}$ Received on April 8, 2008.

Accepted for publication on January 6, 2009.

2 Postgraduate student, Departamento de Clínica Médica, Faculdade de Medicina Veterinária e Zootecnia (FMVZ), Universidade de São Paulo (USP), Av. Prof. Orlando Marques de Paiva 87, São Paulo, SP 05508900, Brazil. *Corresponding author: ggpereira2002@yahoo.com.br

${ }^{3}$ Departamento de Clínica Médica, FMVZ-USP, São Paulo, SP.
}

$1,533 \pm 0,198$, TDE $=88,7 \pm 9,2 \mathrm{~ms}$ e TRIV $=0,080 \pm 0,009 \mathrm{~s}$. Alguns parâmetros foram influenciados pela freqüência cardíaca (Vmáx.E, Vmáx.A e TRIV), pela idade (Vmáx.A e E/A) e pelo peso corpóreo (TRIV). Não houve influência pelo sexo. Os valores obtidos podem ser utilizados como referência para a espécie canina, porém devem ser interpretados considerando-se a influência das variáveis descritas.

TERMOS DE INDEXAÇÃO: Diástole, Doppler pulsátil, cães, ventrículo esquerdo.

\section{INTRODUCTION}

Investigations concerning diastolic cardiac function have experienced increasing relevance in the last years because of diastolic dysfunction's role on heart failure progression (Dougherty et al. 1984, Rihal et al. 1994, Rossi et al. 2004). Diastolic dysfunction is not only found on primary heart disease but also as a consequence of systemic diseases, such as hyperadrenocorticism, chronic renal failure, obesity, and others (Atkins 1999). The study of ventricular diastole allows identification of prognostic indicators and is a valuable tool on therapy follow-up (Werner et al. 1993). 
There are many useful pulsed-wave Doppler derived parameters that allow diastolic function indirect evaluation. Some of them are extremely relevant and easily obtained, like maximum velocities of $E$ (peak $E$ ) and $A$ (peak $A$ ) waves, $E: A$ ratio $(E: A)$, $E$ wave deceleration time (EDT) and isovolumic relaxation time (IVRT) (Nishimura \& Tajik 1997).

Reference values for left ventricular diastolic parameters are obviously relevant for determination of left ventricular diastolic function. However, the evaluation of flows by pulsed wave Doppler may be influenced by a sort of variables, like heart rate, age (Schober \& Fuentes 2001), body weight (Sido et al. 2000) and loading conditions (Yamamoto et al. 1993). Some reference values are described for specific breeds, like Doberman Pinscher (Minors \& O'Grady 1998), German Shepherd and Beagle (Kirberger et al. 1992), but there are also reports including dogs representing a wide range of breeds (Schober \& Fuentes 2001).

Once pulsed-wave Doppler of left ventricular flows is a very useful tool on diastolic function investigation the study reported here proposes to obtain some additional reference values for transmitral diastolic flow parameters in dogs and investigate the influence of heart rate, body weight, age and gender on the values obtained.

\section{MATERIALS AND METHODS}

Fourty adult dogs, 20 males and 20 females, representing different breeds (23 cross-breed, three Poodles, two Labrador Retrievers, Cocker Spaniels, Golden Retrievers and Canadian Shepherds, and one Schnauzer, Brazilian Terrier, Dachshund, Beagle, Lhasa Apso and Yorkshire), aged between 2 and 6 years, weighing from 4,2 to $37,4 \mathrm{~kg}$ (mean $18,3 \mathrm{~kg}$ ), were included in this study. Among them, 14 were maintained at Faculdade de Medicina Veterinária e Zootecnia, Universidade de São Paulo, according to the ethics committee of Universidade de São Paulo, and 26 were pet-owned.

Before data acquisition, animals were evaluated by physical, radiographic, electrocardiographic and echocardiographic examination, as well as complete blood count, urinalysis, serum biochemical profiles, ELISA test for Dirofilaria immitis ${ }^{3}$ antigen and indirect Doppler ultrasonographic arterial blood pressure.

Echocardiographic examination was performed according to the Echocardiography Committee of the Specialty of Cardiology, American College of Veterinary Internal Medicine, and the American Society of Echocardiography recommendations (Boon 1998). Pulsed-wave Doppler transmitral flow was recorded from left caudal parasternal long axis four chamber view, with the sample located in the left ventricle, proximal to the mitral leaflets opening. Simultaneous unidimensional (M) mode recording was performed, at mitral valve level, for correlation of flow with heart cycle (Morcerf 1996). The first diastolic flow was considered as early diastolic flow wave (E wave) and the second flow, as atrial contraction flow wave (A wave). Peak E and A waves velocities, considered as the peak of $E$ and $A$ waves, respectively $(\mathrm{m} / \mathrm{s}), E /$ $A$ ratio and EDT, considered as the time from peak to end of $E$ wave (ms), were obtained.

For IVRT determination flows were obtained by a left caudal parasternal long axis five chamber view, with sample positioned between septal mitral leaflet and left ventricular outflow tract. IVRT

\footnotetext{
${ }^{3}$ Snap, Idexx.
}

represented the time interval (s) between the end of left ventricular systolic flow and begging of diastolic mitral flow (E wave).

Five consecutive measurements were performed, for each parameter, in order of reducing effects from sinus arrhythmia variation.

Data analysis were performed by ANOVA for determination of means and standard deviations. Pearson correlation's test (r) was employed in order to investigate influence of heart rate, age and body weight on these parameters. The mean value from five consecutive measurements was considered for correlation studies with age and body weight, in total of 40 points of analysis. For heart rate study, were considered each one of the five measurements, in total of 200 points of analysis. The coefficients of determination $\left(r^{2}\right)$ were obtained to quantify the variation explained by the influence of the variable investigated. Gender influence was investigated by $t$-Student test for the parametric data and by Mann-Whitney test for the non-parametric data. A significance level of $p<0.05$ was considered.

\section{RESULTS}

Figures 1 and 2 show recordings of mitral flow and IVRT, respectively.

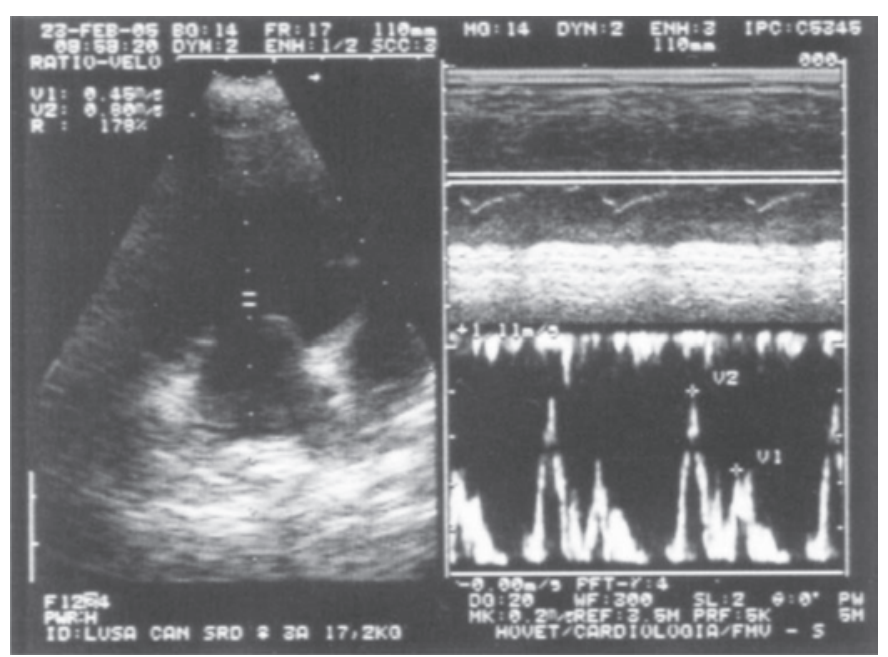

Fig.1. Simultaneous M-mode and pulsed-wave Doppler recording of mitral $E$ and $A$ waves.

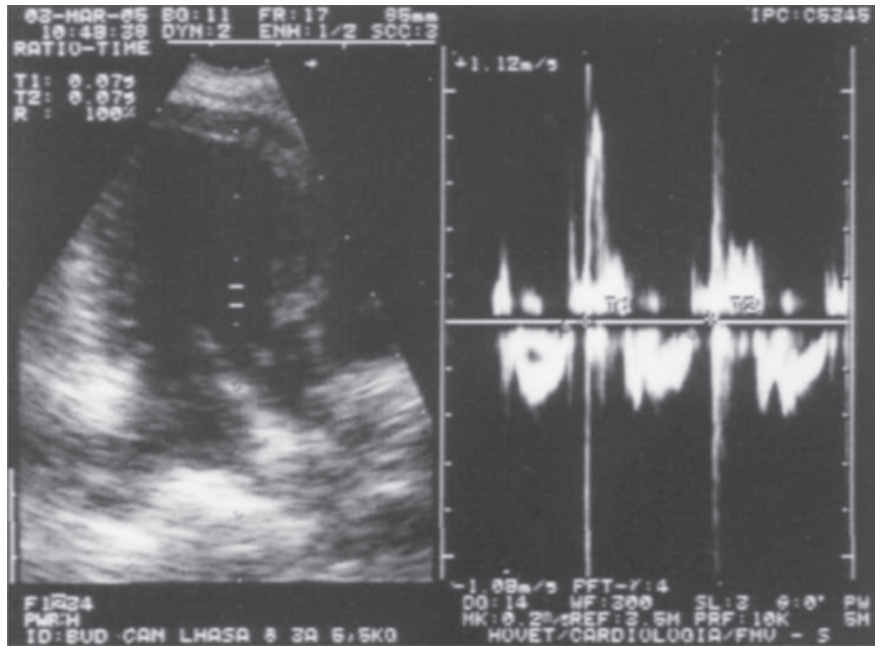

Fig.2. Pulsed-wave Doppler recording of IVRT. 
Table 1. Left ventricular diastolic echocardiographic parameters, obtained by pulsed-wave Doppler, in $\mathbf{4 0}$ healthy dogs

\begin{tabular}{ccccc}
\hline $\mathrm{E}^{\mathrm{a}}(\mathrm{m} / \mathrm{s})$ & $\mathrm{A}(\mathrm{m} / \mathrm{s})$ & $\mathrm{E}: \mathrm{A}$ & $\mathrm{EDT}(\mathrm{ms})$ & IVRT $(\mathrm{s})$ \\
\hline $0.75 \pm 0.117$ & $0.49 \pm 0.062$ & $1.53 \pm 0.198$ & $89 \pm 9.2$ & $0.080 \pm 0.009$ \\
$(0.53-1.06)$ & $(0.39-0.67)$ & $(1.18-1.89)$ & $(74-108)$ & $(0.066-0.100)$
\end{tabular}

$\overline{\mathrm{a} E}=$ peak $\mathrm{E}$ velocity; $\mathrm{A}=$ peak $\mathrm{A}$ velocity; $\mathrm{E}: \mathrm{A}=\mathrm{E}: \mathrm{A}$ ratio; $\mathrm{EDT}=\mathrm{E}$ wave deceleration time; IVRT = isovolumic relaxation time.

Values are expressed as means \pm standard deviation. Range is shown in parentheses.

Table 2. Pearson's correlation coefficients $(r)$ for heart rate, age and body weight influence on left ventricular diastolic echocardiographic parameters

\begin{tabular}{cccccc}
\hline Variable & $\mathrm{E}^{\mathrm{a}}$ & $\mathrm{A}$ & $\mathrm{E}: \mathrm{A}$ & $\mathrm{EDT}$ & IVRT \\
\hline Heart rate & $0.271^{\mathrm{b}}$ & $0.384^{\mathrm{b}}$ & -0.064 & -0.134 & $-0.179^{\mathrm{c}}$ \\
Age & $-0.408^{\mathrm{d}}$ & -0.051 & $-0.428^{\mathrm{d}}$ & -0.196 & 0.012 \\
Body weight & 0.017 & -0.154 & 0.126 & 0.150 & $0.364^{\mathrm{c}}$
\end{tabular}

a $E$ = peak $E$ velocity; $A$ = peak $A$ velocity; $E: A=E: A$ ratio; $E D T=E$ wave deceleration time; IVRT = isovolumic relaxation time; ${ }^{b} p<0.001$; ${ }^{c} p<0.05 ; \quad{ }^{d} p<0.01$.

Values obtained for mentioned parameters studied are expressed as means, standard deviation and range in Table 1.

Pearson's correlation coefficients were calculated and have shown influence of some variables on most of the parameters studied, only excluding EDT (Table 2).

The coefficients of determination $\left(\mathrm{r}^{2}\right)$ for heart rate influence was $0.073,0.147$ and 0.032 for peak $E$, peak $A$ and IVRT, respectively. The $r^{2}$ values of age was 0.166 and 0.183 for peak $E$ and $E: A$ ratio, respectively. Body weight was found to have $\mathrm{r}^{2}=0.132$ for IVRT.

Values of peak E and EDT had parametric distribution in both males and females groups, being investigated by Student's $t$-test, while values of peak A, E:A ratio and IVRT had a non-parametric one, being investigated by MannWhitney's test. No difference was found between both groups at a value of $p<0.05$.

\section{DISCUSSION}

The study revealed referencial values for some left ventricular diastolic parameters in canine specimens, including peak velocities of $E$ and $A$ waves, $E: A$ ratio, $E$ wave deceleration time and isovolumic relaxation time. The examination was performed in conditions that reproduced what is commonly found in clinical practice. The parameters are easily obtained by an experienced examiner and no sedation was required. So, these can be employed in investigations concerning diastolic function in clinical practice. Such parameters are helpful in identification of diastolic abnormalities due to primay or secondary cardiac disorders.

An influence of heart rate, age and body weight on some parameters was found. However, the contribution of these variables alone was low, being the amount of variation in $E: A$ ratio explained by age (18.3\%) the biggest one.
Different sources of variation, like loading conditions, should be involved.

Most of the parameters evaluated were influenced by heart rate. This could be explained by variation in left ventricular filling time, leading to different filling pressures. Although some studies indicated absent (Schober \& Fuentes 2001) or negative (Minors \& O'Grady 1998) correlation between peak $E$ and heart rate, the present study demonstrated a positive correlation. Some authors suggested that atrial pressures are the most important reason for this variation in peak $E$, being heart rate only an indirect component (Yamamoto et al. 1993). Also peak $A$ values were positively correlated with heart rate. This could be explained by the short time to left ventricular filling and increase in residual volume in left atrium after the early filling phase, leading to a higher pressure gradient between both chambers and, consequently, a higher flow velocity. The IVRT demonstrated to shorten with higher heart rates, probably because of early beginning of early left ventricular filling, leading to a premature opening of mitral leaflets.

Age influenced peak $E$ and $E: A$ ratio and older animals showed lower values for the mentioned parameters. $E: A$ reversion was not found in the animals of the study. As were included animals aged under 7 years, the E:A reversion can be considered uncommon and probably abnormal in animals with similar age. Schober and Fuentes (2001) have found reversion in animals aged above 6 years and with no apparent diastolic dysfunction. These findings indicate caution in interpretation of peak $E$ and $E: A$ ratio in elderly animals. Because EDT and IVRT were not influenced by age, it is advisable the concomitant analysis of these parameters when investigating diastolic function in elderly animals.

Body weight positive correlation with IVRT in part could be explained by higher heart rates found in small dogs, once IVRT is also influenced by this variable.

The values obtained can be used as reference for both males and females, once no difference was found between them.

Only EDT was not influenced by any of the variables investigated, on the contrary of some reports (Yamamoto 1993, Schober \& Fuentes 2001). So, it provides valuable information concerning diastolic function in dogs, associated with the others studied parameters.

\section{CONCLUSION}

The present study revealed comparative reference values for left ventricular diastolic parameters in healthy dogs aged between 2 and 6 years and indicated that heart rate, age and body weight, but not gender, should be considered on their interpretation, except for EDT. Additional studies should be performed in order to investigate different sources of influence on these parameters.

\section{REFERENCES}

Atkins C.E. 1999. Cardiac manifestations of systemic and metabolic disease, p.757-780. In: Fox P.R., Sisson D. \& Moïse N.S. (Eds), 
Textbook of Canine and Feline Cardiology: Principles and clinical practice. W.B. Saunders, Philadelphia.

Boon J.A. 1998. Manual of Veterinary Echocardiography. Williams and Wilkins, Baltimore. 478p.

Dougherty A.H., Naccarelli G.V., Gray E.L., Hicks C.H. \& Goldstein R.A. 1984. Congestive heart failure with normal systolic function. Am. J. Cardiol. 54:778-782.

Kirberger R.M., Berg P.B. \& Grimbeek R.J. 1992. Doppler echocardiography in the normal dog. Vet Radiol Ultrasound 33(6):380-386

Minors S.L. \& O'Grady M.R. 1998. Resting and dobutamine stress echocardiographic factors associated with the development of occult dilated cardiomyopathy in healthy Doberman Pinscher dogs. J. Vet. Int. Med. 12:369-380.

Morcerf F.A.P. 1996. Avaliação do tamanho e função do ventrículo esquerdo, p.193-225. In: __ (Ed.), Ecocardiografia Uni-Bidimensional, Transesofágica e Doppler. $2^{\mathrm{a}}$ ed. Revinter, Rio de Janeiro.

Nishimura R.A., Abel M.D., Hatle L.K., Holmes D.R., Housmans P.R., Ritman E.L. \& Tajik A.J. 1989. Significance of Doppler indices of diastolic filling of the left ventricle: Comparison with invasive hemodynamics in a canine model. Am. Heart J. 118(6):1248-1258.

Nishimura R.A. \& Tajik A.J. 1997. Evaluation of diastolic filling of left ventricle in health and disease: Doppler echocardiography is the clinician's Rosetta Stone. J. Am. Coll. Cardiol. 30(1):8-18.

Rihal C.S., Nishimura R.A., Hatle L.K., Bailey K.R. \& Tajik A.J. 1994. Systolic and diastolic dysfunction in patients with clinical diagnosis of dilated cardiomyopathy. Relation to symptoms and prognosis. Circulation 90(6):2772-2779.

Schober K.E. \& Fuentes V.L. 2001. Effects of age, body weight, and heart hate on transmitral and pulmonary venous flow in clinically normal dogs. Am. J. Vet. Res. 62(9):1447-1454.

Sido Z., Jako P. \& Pavlik G. 2000. The effect of moderate weight loss on echocardiographic parameters in obese female patients. Acta Physiol. Hung. 87(3):241-251.

Yamamoto K., Mauyama T., Tanouchi J., Uematsu M., Doi Y., Naito J., Hori M., Tada M. \& Kamada T. 1993. Importance of left ventricular minimal pressure as a determinant of transmitral flow velocity pattern in the presence of left ventricular systolic dysfunction. J. Am. Coll. Cardiol. 21(3):662-672.

Werner G.S., Scaefer C., Dirks R., Figulla H.R. \& Kreuzer H. 1993. Doppler echocardiographic assessment of left ventricular filling in idiopathic dilated cardiomyopathy during a one-year follow-up: Relation to the clinical course of disease. Am. Heart J. 126(6):1408-1416. 